\title{
PRIMARY SPLENIC HYDATID IN AN ADULT FEMALE
}

Shashidhara $\mathrm{P}^{1}$, Harish Kumar $\mathrm{C}^{2}$, Seshasayi $\mathrm{M}^{3}$

\section{HOW TO CITE THIS ARTICLE:}

Shashidhara P, Harish Kumar C, Seshasayi M. "Primary Splenic Hydatid in an Adult Female". Journal of Evolution of Medical and Dental Sciences 2014; Vol. 3, Issue 63, November 20; Page: 13950-13952,

DOI: $10.14260 /$ jemds/2014/3866

ABSTRACT: Hydatid disease in humans commonly affects the liver and lungs. Primary splenic hydatid cyst is rare. It may occur in association with hepatic, pulmonary or multi-organ hydatidosis. We report the unusual case of isolated primary splenic hydatid cyst in a 56year-old female who presented with the history of left upper abdominal mass and pain. Ultrasonography revealed mixed echoic splenic mass lesion probably hydatid with daughter cysts, which was confirmed on computed tomography scan and ultrasound. Radiographic imaging studies did not show any cyst in liver, lungs or kidneys. Splenectomy was performed with an uneventful recovery.

KEYWORDS: Primary splenic hydatid, ecchinicoccus granulosus.

CASE REPORT: A 56 yrs old female with occupational history of rearing sheep, presented to us with a complaints of progressively increasing upper abdominal mass and pain of 3 months duration. General physical examination of patient was normal. Abdominal examination revealed moderate splenomegaly. Ultrasonography revealed multiple mixed echoic splenic mass lesion measuring $6 \mathrm{~cm}$, probably hydatid with daughter cysts, which was confirmed on computed tomography scan.

Radiographic imaging studies did not show any cyst in liver, lungs or kidneys. Elective splenectomy was planned. Splenectomy was performed by Left upper transverse incision. There were some adhesions of the spleen to parietal wall. After careful dissection and adhesiolysis, splenectomy was performed successfully. Postoperative stay in the hospital was uneventful and the patient was discharged of 8th postoperative day.

Our patient received albendazole $(10 \mathrm{mg} / \mathrm{kg} /$ day $)$ for one month prior to surgery and in the postoperative period as three cycles of 4 weeks each with one-week drug-free intervals between each cycle of albendazole. She also received pneumococcal vaccine 2-3 weeks before the surgery, to allow development of protective antibodies. Patient was in good health at 6, 10 and 14 weeks of follow up.

DISCUSSION: Hydatid disease (aka: echinococcosis), is a zoonosis that occurs primarily in sheep grazing areas of the world, but is nevertheless common worldwide. Man is an accidental host in the life cycle of Echinococcus granulosus. Human infestation occurs due to ingestion of eggs. Larva liberated from eggs penetrates the bowel mucosa to enter the portal system thereby spreading to various organs.

Hydatid cysts represent nearly two-thirds of cystic lesions of the spleen. ${ }^{[1-3]}$ However, splenic hydatid cysts account for only $0.5 \%$ to $8 \%$ of all hydatidosis. ${ }^{[4,2]}$ Splenic hydatid cysts occur in $1.5 \%$ to $3.5 \%$ of all cases of abdominal hydatidosis.[5,6] Splenic hydatid cysts are mostly solitary[5] but may sometimes be multiple,[4] and may be associated with cysts in other viscera in up to $30 \%$ of cases.[6-8] The parasite may reach the spleen through blood stream, through lymphatics ${ }^{[4]}$ and by reflux into the spleen from portal vein at the time of raised intraabdominal pressure.[9] 
Isolated involvement of spleen is rare. Primary infestation of the spleen usually takes place by the arterial route after the parasite has bypassed the liver and lungs.

Approximately $30 \%$ of splenic cysts are asymptomatic. The most common finding is incidentally discovered splenomegaly.[9] The symptoms are non-specific,[10]and include an abdominal mass, dull dragging ache, dyspepsia, constipation due to pressure on colon, and dyspnea due to pushing up of the left diaphragm. Some patients may present with complications such as infection of the cyst, rupture of the cyst into the peritoneal cavity, fistula formation into hollow viscera like colon or stomach, bronchopleural fistula, sympathetic pleural effusion, calcification, hypersplenism, and severe urticaria.

Serum immunoelectrophoresis is currently the most reliable serological test, with a sensitivity of approximately $90 \%$. It stays positive for up to one year after the infection has been eradicated. Indirect hemagglutinition test has a sensitivity of $85 \%$ but remains positive for several years.[1] Complement fixation, enzyme linked immunosorbent assay (ELISA), western blot analysis and Casoni skin test are other tests that are done. For our patient we did ELISA which was positive.

The treatment is principally surgical. Splenectomy has been the treatment of choice for splenic hydatid cysts since it is effective. Pre- and postoperative administration of albendazole used to sterilize the cyst, reduce the risk of anaphylaxis by destroying the scolices, decrease the tension in the cyst wall and to reduce the postoperative recurrence rate.[3] Intra-operatively, hypertonic saline or $0.5 \%$ silver nitrate is instilled into the cyst before opening it; this tends to kill the daughter cysts, thereby preventing further spread and anaphylactic reaction. ${ }^{[3]}$

Conservative surgery like partial splenectomy, cyst enucleation, deroofing of the cyst with omentoplasty or external drainage of the cyst can be done for superficial cysts, cysts located in one pole of the spleen. $[7,8]$

We conclude that Splenic Hydatid although rare should always be kept in mind while dealing with cystic lesions of the spleen especially in endemic areas. Open Splenectomy is the gold standard for splenic hydatid and use of albendazole both preoperatively and postoperatively may reduce the risk of recurrence by destroying the scolices.

\section{REFERENCES:}

1. Wani RA, Malik AA, Chowdri NA, Wani KA, Naqash SH. Primary extrahepatic abdominal hydatidosis. Int J Surg. 2005; 3:125-7.

2. Amr SS, Amr ZS, Jitawi S, Annab H. Hydatidosis in Jordan: an epidemiological study of 306 cases. Ann Trop Med Parasitol. 1994; 88:623-7.

3. Kune GA, Morris DL. Hydatid disease. In: Schwartz SI, Ellis H, editors. Maingots abdominal operations. London: Appleton and Lange; 1990. p. 1225-40.

4. Ammann RW, Eckert J. Cestodes. Echinococcus. Gastroenterol Clin North Am. 1996; 25: 655-89.

5. Shukla RA, Hathia WP, Dadhagara KM. Hydatid disease in Saurashtra study of 210 cases. In: Saksena DS, Jhawar DK, Purohit A, editors. Surgery in the Tropics. New Delhi: Macmillan; 1991. p. 450-60.

6. Durgun V, Kapan S, Kapan M, Karabiçak I, Aydogan F, Goksoy E. Primary splenic hydatidosis. Dig Surg. 2003; 20:38-41. 


\section{CASE REPORT}

7. Safioleas M, Misiakos E, Manti C. Surgical treatment for splenic hydatidosis. World J Surg. 1997; 21:374-7.

8. Ozdogan M, Baykal A, Keskek M, Yorgancy K, Hamaloglu E, Sayek I. Hydatid cyst of the spleen: treatment options. Int Surg. 2001; 86:122-6.

9. Singh H, Arora S. Primary hydatid cyst of the spleen. Med J Armed Forces India. 2003; 59:16970.

10. Varghese C, Balakrishnan V. Hydatid cyst of the spleen-an unusual presentation. J Assoc Physicians India. 1979; 27:1039-41.

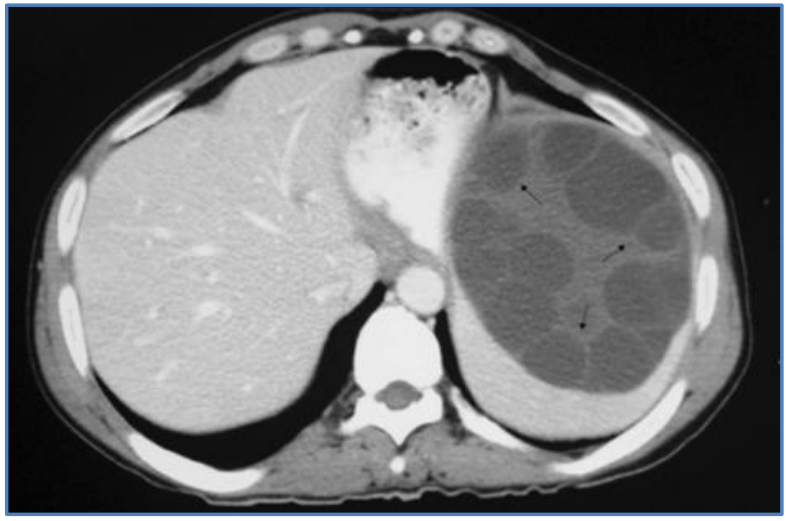

Fig. 1: CT picture of our patient ShowingSplenomegaly and arrows pointing daughter cysts

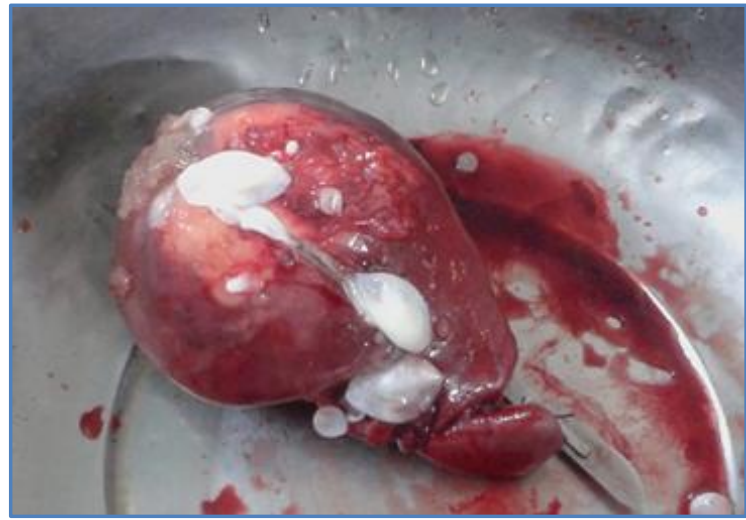

Fig. 2: Splenectomy specimen, on cut section showing daughter cysts

\section{AUTHORS:}

1. Shashidhara P.

2. Harish Kumar C.

3. Seshasayi M.

\section{PARTICULARS OF CONTRIBUTORS:}

1. Assistant Professor, Department of Surgery, RRMCH, Bangalore.

2. Assistant Professor, Department of Surgery, RRMCH, Bangalore.

3. Professor, Department of Surgery, RRMCH, Bangalore.

\section{NAME ADDRESS EMAIL ID OF THE CORRESPONDING AUTHOR:}

Dr. Shashidhara $P$, $33 / 1,1^{\text {st } ~} \mathrm{~B}$ ' Cross, $5^{\text {th }}$ Block, Banashankari $3^{\text {rd }}$ stage, Bangalore-560085.

Email:dr.shashi85@gmail.com

Date of Submission: 30/10/2014. Date of Peer Review: 31/10/2014. Date of Acceptance: 14/11/2014. Date of Publishing: 20/11/2014. 